\title{
Tighter watch urged on adenoviral vectors...
}

Washington

Gene-therapy researchers using adenoviral vectors should apply stricter quality controls and more precise monitoring to them because of the 'narrow window' that separates their potential efficacy from toxicity, an advisory panel of the US National Institutes of Health concluded provisionally last week.

The Recombinant DNA Advisory Committee (RAC) met to examine the factors that led to the first death attributed directly to gene therapy (see Nature 401, 517; 1999). But the panel also analysed the field as a whole, hearing testimony from a host of researchers who have used the vector in clinical trials.

Many repeatedly mentioned the 'window' and the 'threshold effect' associated with it - that one dose level may cause little or no adverse effect in patients, but a slightly higher dose may trigger apparently disproportionate reactions. Those reactions include immune responses resulting in influenza-like symptoms and tissue damage to the organ in which the vector was administered.

Both of these occurred after Jesse Gelsinger, an 18-year-old Arizona man, received one of the highest doses of adenoviral vector ever given to a human, to treat a partial defect of the gene that encodes ornithine transcarbamylase, an enzyme that removes ammonia from the liver.

Shortly after receiving the vector, Gelsinger developed a high fever. Within the first day, tests showed that he had suffered liver injury and inappropriate blood coagulation. These symptoms had begun to improve when, on the third day, Gelsinger started to have trouble breathing. His vita organs were failing, and his doctors took him off life support on the fourth day.

Inder Verma, a gene-therapy researcher with the Salk Institute in La Jolla, California, and co-chair of the RAC, said he was struck not with the similarities among groups, but with the differences. Some groups measured the strength of their doses in infectious units, while others used particles per kilogram.

"There was really no standard," Verma says, which makes measuring the strength and potential toxicity of one vector against another very difficult. Many gene-therapy researchers also seem unclear about their end points, such as how much messenger RNA ends up in targeted cells after gene therapy.

That end point in the experiment that led to Gelsinger's death was one of many "surprising" findings, according to James Wilson, director of the University of Pennsylvania's Institute for Human Gene Therapy, who oversaw the trial.

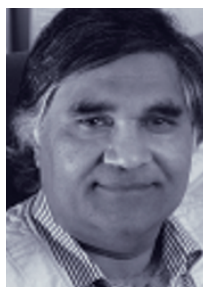

Verma: 'no standard' for measuring doses.

$$
\text { The autopsy also }
$$

revealed further abnormalities in Gelsinger's bone marrow, indicating that he may have also been infected with a parvovirus, which, when combined with the adenovirus, may have initiated the chain reaction of adverse events. Finally, when Wilson examined the vector used to carry the gene that codes for ornithine transcarbamylase, he discovered duplicate sequences not engineered in the original.
The RAC concluded that such anomalies underscore the need for more careful measurement at all stages of gene-therapy trials. "Toxicities vary from study to study, vector to vector, patient type to patient type," says RAC member Robert Warren, an oncologist with the University of California at San Francisco.

In its preliminary findings, the RAC advised gene-therapy researchers to take more safety measures, including checking the sequence integrity of a vector before administration, monitoring cytokine levels more closely before and after gene therapy begins, and ensuring that patients have no additional virus lurking in their systems.

Researchers administering adenoviral vectors directly into organs should also consider smaller increases between doses, so that there is less danger when they approach the toxicity threshold.

Paul Smaglik

\section{... with proposal to report all 'adverse events'}

\section{Washington}

The Recombinant DNA Advisory Committee (RAC) of the National Institutes of Health has been urged to recommend that gene-therapy researchers be required to report all 'adverse events' occuring during their trials, whether or not they are related to the treatment the patients are receiving.

The proposal came during a three-day meeting that discussed the death earlier this year of Jesse Gelsinger (see above). Committee officials struggled to define how much information gene-therapy researchers must submit, both publicly and privately, and admitted that those involved in the Gelsinger trial failed on both fronts.

On the public front, the researchers did not report to the RAC a change in the clinical trial's protocol. The committee had approved the protocol to treat ornithine transcarbamylase deficiency with an adenoviral vector administered intravenously.

But when the RAC was temporarily disbanded in 1996, the US Food and Drug Administration (FDA), with the researchers' cooperation, changed the route of administration. The vector was now to be administered in an artery leading directly to the liver in an effort to minimize the problem of the vector's wide distribution throughout the body.

"We recognize that we probably should have come to the RAC" after the protocol change, says Mark Batshaw, chief academic officer at Children's National Medical Center in Washington. By the time the trial was under way in 1997, a revived but weakened RAC had lost its authority to approve most genetherapy clinical trials.

Kathryn Zoon, director of the FDA's Center for Biologics Evaluation and Research, presented "preliminary evidence of approximately two protocol violations" by the researchers. Both involved failure to disclose information to the FDA.

First, the researchers decided to treat Gelsinger despite levels of ammonia in his liver that were higher than the limits allowed for enrolment.

James Wilson, director of the Institute for Human Gene Therapy at the University of Pennsylvania in Philadelphia, where the trial was conducted, defended the decision, saying that Gelsinger's ammonia level at the time of enrolment was fine, technically meeting the requirement of the written protocol. The researchers also treated Gelsinger to reduce the level before he received the vector. Wilson also initially denied the second charge - that the researchers should have notified the FDA within two weeks when two patients, each of whom received a smaller dose than Gelsinger, had shown higher than normal levels of liver enzymes.

Wilson pointed out that the group had immediately notified the FDA about two previous patients with similar problems, and agency representatives had allowed the trial to continue. He also said he had filed a written report detailing the liver enzymes eight months before treating Gelsinger.

But Steven Raper, associate professor of surgery at the University of Pennsylvania, accepted the next day that they "should have called the FDA" about each of the patients.

To prevent further such confusion over the reporting rules, the RAC considered a proposal that gene-therapy researchers should publicly disclose all adverse effects that accompany gene therapy.

The proposal goes beyond FDA requirements, as it would require disclosure on both expected and unexpected adverse events in the clinical protocol, regardless of whether they are directly related to the treatment. 